\title{
KAJIAN EKOSISTEM HUTAN MANGROVE DI MUARA SUNGAI BATANG MANGGUNG KECAMATAN PARIAMAN UTARA KOTA PARIAMAN PROVINSI SUMATERA BARAT
}

\author{
Novelisa Suryani ${ }^{1}$ \\ 1Program Studi Geografi Universitas Tamansiswa Padang \\ Jl. Tamansiswa No. 9 Padang, Sumatera Barat 25138 \\ Email: novel2813@gmail.com
}

\begin{abstract}
Abstrak
Penelitian ini memiliki tujuan untuk: (i) mengkaji karakteristik vegetasi dan kerusakan ekosistem hutan mangrove, dan (ii) mengkaji kondisi fisik-kimia ekosistem hutan mangrove. Metode perolehan sampel menggunakan teknik purposive sampling. Data karakteristik vegetasi diperoleh melalui metode transek dan petak contoh. Data ini dijadikan acuan dalam menentukan tingkat kerusakan ekosistem mangrove. Kondisi fisikkimia diperoleh melalui pengukuran lapangan dan analisis laboratorium.Hasil penelitian menunjukkan INP paling tinggi untuk tingkat pohon terdapat pada Xylocarpus rumphii (133,8\%), yang dijumpai di Stasiun I. Spesies yang umumnya mendominasi pada tingkat pancang yaitu Sonneratia caseolaris, dengan INP 46,19\% pada Stasiun III, sedangkan mayoritas spesies pada tingkat semai dan tumbuhan bawah yaitu Rhizophora mucronata, dengan INP 66,32\% pada Stasiun II. Ekosistem mangrove untuk tingkat pohon termasuk dalam kategori rusak, dengan penutupan $<50 \%$ dan kerapatan $<1000$ pohon/ha. Sementara, pada tingkat pancang, semai dan tumbuhan bawah, termasuk dalam kategori baik dengan kerapatan individu $>1500$ pohon/ha. Kondisi $p H$ perairan dan suhu udara kurang mendukung untuk perkembangan dan pertumbuhan vegetasi mangrove, sedangkan parameter lain memiliki kondisi yang sudah sesuai.
\end{abstract}

Kata kunci: ekosistem mangrove, fisik-kimia, INP, karakteristik vegetasi

\begin{abstract}
This study aims to : (i) examined vegetation characteristic and the damage degree of mangrove ecosystems, (ii) examined the physical-chemical condition of mangrove ecosystems, and (iii) analyse the used of mangrove for environment and communities. This research is conducted in the surroundings mouth of Batang Manggung River, Pariaman Utara Subdistrict, Pariaman City. The sampling technique is purposive sampling. Vegetation characteristic data obtained trough line transect and plot sampling. This data is used to be reference in determine the damage degree of mangrove ecosystems. Physical-chemical data obtained trough field measured and laboratorium analysis. The results show that the value of INP at highest rate for tree level was Xylocarpus rumphii $(133,8 \%)$ at Stasiun I. The most dominated species for sapling is Sonneratia caseolaris, which $46,19 \%$ of INP at Stasiun III. The seedling and herbs dominate with Rhizhophora mucronata, which $66,32 \%$ of INP at Stasiun II. The tree level include in damage category, which $<50 \%$ covered area and the density $<1000$ tree/ha. For sapling, seedling and herbs include in good category, which density was $>1500$ tree/ha. The water $p H$ and air temperature had less support in extent and growth of mangrove, while the other parameter had suitable.
\end{abstract}

Keywords: mangrove ecosystems, physical-chemical, vegetation charactersitic, IVI 


\section{PENDAHULUAN}

Ekosistem hutan mangrove mengalami ancaman baik oleh faktor alam maupun manusia, sehingga menimbulkan risiko bagi kelangsungan hidup ekosistem ini dalam jangka panjang (Dale et al., 2014). Kurang lebih $70 \%$ hutan mangrove Indonesia mengalami ancaman akibat tidak adanya regulasi. Regulasi ini akan melibatkan berbagai stakeholder karena ekosistemnya berada pada bentang alam yang berbeda yaitu darat dan laut (Kustanti et al., 2014).

Mangrove merupakan ekosistem yang hidup dekat dengan sungai, daerah pasang surut, teluk, muara, laguna dan vegetasinya dapat beradaptasi terhadap kandungan garam yang tinggi (Onrizal 2008; Feka, 2015). Sistem perakaran vegetasi mangrove dapat mengikat sedimen dan menstabilkan substrat. Mangrove juga mampu menjaga keseimbangan dan kelangsungan ekosistem pesisir dan lautan serta rantai makanan (Armono, 1996). Sebagai salah satu potensi di wilayah pesisir, mangrove memiliki berbagai manfaat bagi masyarakat di sekitar berupa sosial ekonomi dan ekologi (Faturrohmah dan Marjuki, 2017).

Kota Pariaman sebagian besar wilayahnya berada di sepanjang pesisir pantai. Salah satu sumberdaya yang dimiliki wilayah ini berupa hutan mangrove yang terdapat pada tiga kecamatan, yaitu Kecamatan Pariaman Tengah, Kecamatan Pariaman Selatan dan Kecamatan Pariaman Utara. Namun, luas area hutan mangrove di Kota Pariaman mengalami fluktuasi akibat peningkatan aktivitas pembangunan, terutama di wilayah pesisir.

Menurut Dinas Kelautan dan Perikanan (2012), hutan mangrove di Kota Pariaman hanya 18 ha. Kecamatan Pariaman Utara memiliki hutan mangrove yang paling luas yaitu 16,5 ha, tersebar di Desa Apar (6,0 ha), Desa Ampalu (3,5 ha) dan Desa Manggung (7,0 ha). Menurut Ramdhan dan Abdillah (2012) wilayah pesisir Kota Pariaman memiliki tingkat kerentanan fisik yang sangat tinggi. Terdapatnya konsentrasi pemukiman di sepanjang wilayah pesisir, kemiringan pantai yang landai, serta tingkat abrasi yang cukup tinggi merupakan pemicu kondisi ini. Tingkat kerentanan akan semakin tinggi apabila ekosistemmangrove yang memiliki fungsi sebagai pelindung wilayah pesisir mengalami degradasi.

Salah satu ekosistem mangrove yang mengalami degradasi menempati wilayah di sekitar muara Sungai Batang Manggung, Kecamatan Pariaman Utara. Survei lapangan awal menunjukkan fakta bahwa beberapa lokasi di muara Sungai Batang Manggung terdapat beberapa pohon mangrove yang mati dan tidak tumbuh dengan baik. Dugaan awal disebabkan karena berkurangnya aliran air tawar dari hulu sungai. Terganggunya sirkulasi air pada ekosistem mangrove menyebabkan ketidakseimbangan pada kondisi fisik-kimia pada habitat mangrove.

Secara umum tujuan penelitian ini yaitu (1) mengkaji karakteristik vegetasi dan tingkat kerusakan ekosistem hutan mangrove di muara Sungai Batang Manggung; (2) mengkaji kondisi fisikkimia ekosistem hutan mangrove di muara Sungai Batang Manggung.

\section{METODE PENELITIAN}

Penelitian ini tergolong pada jenis penelitian kombinasi, yang menggabungkan penelitian kuantitatif dan kualitatif. Pengambilan data primer dilakukan dengan menggunakan alat bantu berupa daftar ceklis pada saat pengukuran lapangan dan daftar wawancara. Data sekunder diperoleh dari berbagai literatur dan instansi seperti Bappeda, Badan Lingkungan Hidup, Dinas Kelautan dan Perikanan, serta Badan Pusat Statistik.

Penelitian dilakukan di sekitar muara Sungai Batang Manggung yang berada pada wilayah administratif Desa Apar dan Desa Ampalu, Kecamatan Pariaman Utara (Gambar 1). Lokasi ini 
dipilih karena terdapatnya campurtangan

wilayah tersebut. manusia terhadap ekosistem mangrove di

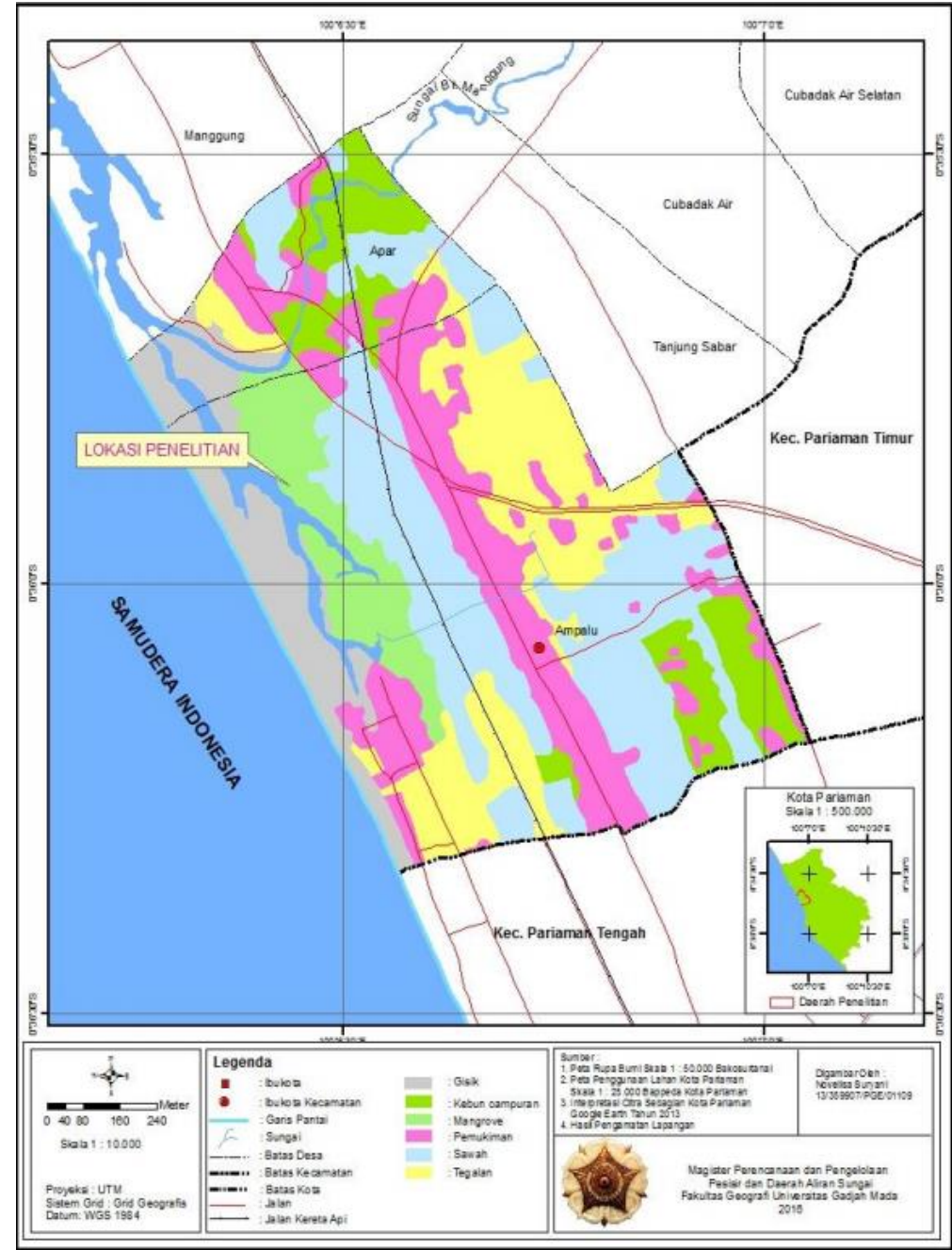

Gambar 1. Lokasi Penelitian

\section{Bahan Penelitian}

Bahan yang digunakan dalam penelitian ini diantaranya ;

1. Peta Administratif Kota Pariaman Tahun 2005, untuk mengetahui batas administrasi wilayah penelitian.

2. Citra satelit resolusi tinggi dari Google Earth, sebagian Kota Pariaman, tanggal perekaman 27 Agustus 2013, untuk menentukan titik pengambilan sampel.

3. Buku pengenalan mangrove, untuk mengidentifikasi jenis mangrove di lapangan.

\section{Alat Penelitian}

Peralatan yang digunakan dalam penelitian ini adalah GPS, tali rafia dan tiang, botol sampel $600 \mathrm{ml}$, Thermo- hygrometer, sekop tangan, plastik sampel, plastik besar, $\mathrm{pH}$ stik, kertas label dan spidol permanen, daftar checklist dan tally sheet, daftar wawancara, alat tulis, kamera digital, perangkat keras berupa komputer dan pencetak, serta software ArcGIS 9.3.1, dan SPSS versi 16.

\section{Teknik Pengumpulan Data}

Pengambilan sampel menggunakan teknik purposive sampling, yang disesuaikan dengan tujuan penelitian. Sampel vegetasi, dan fisik-kimia ekosistem mangrove menggunakan metode Line Transect Plot (Transek Garis dan Petak Contoh). Transek garis dilakukan pada tiga stasiun pengamatan. Stasiun I berada di sekitar muara sungai, 
berdekatan dengan pintu penyaluran air, baik yang berasal dari laut maupun sungai. Stasiun II terletak di tengah areal hutan mangrove dengan kondisi lebih banyak mendapat pasokan air tawar. Stasiun III berbatasan dengan pemukiman warga dan area konservasi penyu (Gambar 2).

Mekanisme pengukuran vegetasi mangrove didasarkan pada Pedoman Penentuan Kerusakan Mangrove dari Kepmen LH No. 201 Tahun 2004. Vegetasi mangrove diidentifikasi berdasarkan ukuran permudaan, yaitu pohon, pancang, semai dan tumbuhan bawah. Ukuran sub-petak untuk setiap tingkat permudaan yaitu: (i) semai dan tumbuhan bawah: $2 \times 2 \mathrm{~m}$; (ii) pancang: $5 \times 5 \mathrm{~m}$; dan (iii) pohon: $10 \times 10 \mathrm{~m}$.

Kondisi fisik-kimia berupa DO dan salinitas diambil dengan cara memasukkan sampel air ke dalam botol $600 \mathrm{ml}$ pada setiap titik sampel yang berjumlah 9 titik. Sampel ini kemudian dianalisis lebih lanjut di Laboratorium Air Jurusan Teknik Lingkungan, Fakultas Teknik, Universitas Andalas.

Suhu udara dapat diukur langsung di lapangan, begitu juga dengan $\mathrm{pH}$ air. Jenis subtrat dan kandungan organik subtrat diperoleh dari sampel sedimen dengan kedalaman $30 \mathrm{~cm}$. Sampel sedimen kemudian dianalisis lebih lanjut di Laboratorium Balai Pengkajian Teknologi Pertanian Sumatera Barat.

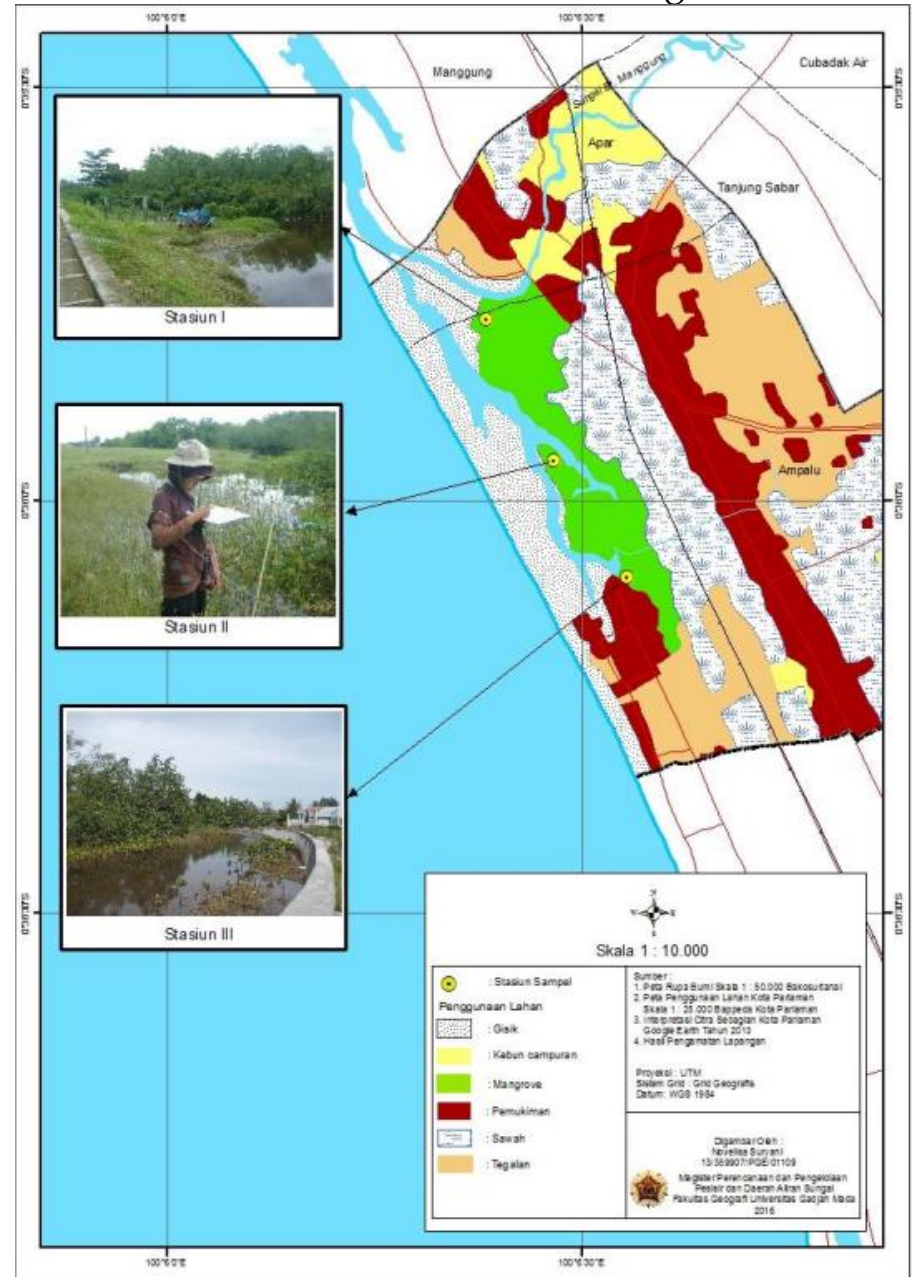

Gambar 2. Lokasi Transek

Teknik analisis data untuk mengetahui karakteristik vegetasi mangrove dilakukan dengan cara mengidentifikasi spesies mangrove yang ditemukan di lokasi transek dan dicocokkan dengan Pedoman Pengenalan Mangrove. Langkah selanjutnya yaitu menghitung Indeks Nilai Penting (INP). 
Nilai penting memberikan gambaran peranan suatu jenis tumbuhan dalam suatu komunitas. Formula yang digunakan untuk menentukan INP menurut Onrizal (2008) yaitu :

(1) Kerapatan suatu jenis (K) (ind/ha)

$$
\mathrm{K}=\frac{\text { individusuatujenis }}{\text { luaspetakcontoh }}
$$

(2) Kerapatan relatif suatu jenis (KR) $(\%)$

$$
\mathrm{KR}=\frac{\text { Ksuatujenis }}{\text { Kseluruhjenis }} \times 100 \%
$$

(3) Frekuensi suatu jenis $(\mathrm{F})$

$\mathrm{F}=\frac{\sum \text { Sub-petakditemukansuatujenis }}{\sum \text { Seluruhsub-petakcontoh }}$

(4) Frekuensi relatif suatu jenis (FR) (\%)

$$
\mathrm{FR}=\frac{\text { Fsuatujenis }}{\text { Fseluruhjenis }} \times 100 \%
$$

(5) Dominansi suatu jenis (D) ( $\left.\mathrm{m}^{2} / \mathrm{ha}\right)$. D hanya dihitung untuk tingkat pohon. $\mathrm{D}=\frac{\text { Luasbidangdasarsuatujenis }}{\text { Luaspetakcontoh }}$

(6) Dominansi relatif suatu jenis (DR) $(100 \%)$

$$
\mathrm{DR}=\frac{\text { Dsuatujenis }}{\text { Dseluruhjenis }} \times 100
$$

(7) Indeks Nilai Penting (\%)
(a) Tingkat Pohon:
$\mathrm{INP}=\mathrm{KR}+\mathrm{FR}+\mathrm{DR}$

(b) Tingkat semai, pancang dan tumbuhan bawah

$\mathrm{INP}=\mathrm{KR}+\mathrm{FR}$

Formula yang digunakan dalam analisis penutupan tumbuhan yaitu:

(1) Penutupan Jenis (Ci)

$\mathrm{Ci}=\frac{\sum B A}{A}$

$\mathrm{Ci} \quad$ : Penutupan jenis

$\sum$ BA $: \Pi \mathrm{DBH}^{2} / 4\left(\right.$ dalam $\left.\mathrm{cm}^{2}\right), \Pi=$

3,1416

$\mathrm{DBH}$ : diameter batang pohon dari jenis i

A : luas total area pengambilan contoh

(2) Penutupan relatif (Rci)

$\sum \mathrm{RCi}=\frac{C i}{\sum C} \mathrm{X} 100 \%$

$\sum$ Rci : penutupan relatif

$\sum \mathrm{C} \quad$ : penutupan total untuk seluruh jenis

Persentase tutupan mangrove digunakan dalam menentukan kriteria atau status kerusakan hutan mangrove. Kriteria baku kerusakan mangrove tercantum dalam Kepmen LH. No. 201 Tahun 2004, seperti tertera pada Tabel 1.

Tabel 1. Kriteria Baku Kerusakan Mangrove

\begin{tabular}{|l|l|l|l|}
\hline \multicolumn{2}{|l|}{ Kriteria } & $\begin{array}{l}\text { Penutupan } \\
\text { (\%) }\end{array}$ & $\begin{array}{l}\text { Kerapatan } \\
\text { (pohon/ha) }\end{array}$ \\
\hline \multirow{3}{*}{ Baik } & $\begin{array}{l}\text { Sangat } \\
\text { Padat }\end{array}$ & $>75$ & $>1500$ \\
\cline { 2 - 4 } & Sedang & $>50-<75$ & $\begin{array}{l}>1000 \\
<1500\end{array}$ \\
\hline Rusak & Jarang & $<50$ & $<1000$ \\
\hline
\end{tabular}

Sumber: Kepmen LH. No. 201 Tahun 2004

Penentuan parameter fisik-kimia ekosistem mangrove dilakukan dengan cara membandingkan dan mencocokkan data parameter lingkungan yang diperoleh, baik dari hasil pengukuran lapangan maupun analisis laboratorium, dengan kesesuaian jenis-jenis mangrove berdasarkan beberapa literatur. Adapun kesesuaian kondisi-fisik kimia ekosistem mangrove dapat dilihat pada Tabel 2.
Setelah dilakukan analisis terhadap tingkat kesesuaian beberapa jenis vegetasi mangrove dengan Tabel 2, maka akan diketahui apakah parameter fisik-kimia ekosistem mangrove muara Sungai Batang Manggung melebihi ambang batas atau tidak. Selanjutnya, untuk mengetahui apakah terdapat perbedaan kondisi fisikkimiaperairan dan substrat mangrove pada masing-masing stasiun, maka dilakukan uji statistik menggunakan uji $t$ 
test satu sampel menggunakan perangkat SPSS versi 16. Hasil temuan ini selanjutnya akan dianalisis secara deskriptif.

Tabel 2.Kesesuaian Kondisi Fisik-Kimia Ekosistem Mangrove

\begin{tabular}{|c|c|c|c|c|c|c|c|}
\hline \multirow[t]{2}{*}{ No } & \multirow[t]{2}{*}{ Spesies } & \multicolumn{6}{|c|}{ Kondisi Fisik-Kimia } \\
\hline & & $\begin{array}{c}\mathrm{DO} \\
(\mathrm{mg} / \mathrm{l})\end{array}$ & $\begin{array}{c}\text { Salinitas } \\
(\% 0)^{* *}\end{array}$ & $\mathrm{pH}_{* *}$ & $\begin{array}{l}\text { Suhu } \\
\text { udara } \\
\left({ }^{\circ} \mathrm{C}\right)\end{array}$ & Substrat & $\begin{array}{c}\text { Bahan } \\
\text { Organik } \\
(\%) \\
* * * *\end{array}$ \\
\hline 1 & $\begin{array}{l}\text { Acanthus } \\
\text { ilicifolius }\end{array}$ & $>5$ & $0-34$ & $7-8,5$ & $28-32^{* *}$ & $\underset{* * * * *}{\text { Berpasir }}$ & $0,50-1,46$ \\
\hline 2 & $\begin{array}{l}\text { Nypa } \\
\text { fruticans }\end{array}$ & $>5$ & $0-34$ & $7-8,5$ & $28-32^{* *}$ & $\begin{array}{c}\text { Berpasir, } \\
\text { berdebu, } \\
\text { liat } \\
\text { berdebu, } \\
\text { liat } * * *\end{array}$ & $0,50-1,46$ \\
\hline 3 & $\begin{array}{l}\text { Rhizophora } \\
\text { mucronata }\end{array}$ & $>5$ & $0-34$ & $7-8,5$ & $26-28^{*}$ & $\begin{array}{c}\text { Berpasir, } \\
\text { berdebu, } \\
\text { liat } \\
\text { berdebu } \\
\quad * * *\end{array}$ & $0,50-1,46$ \\
\hline 4 & $\begin{array}{l}\text { Sonneratia } \\
\text { caseolaris }\end{array}$ & $>5$ & $0-34$ & $7-8,5$ & $28-32^{* *}$ & $\begin{array}{c}\text { Koral, } \\
\text { berpasir, } \\
\text { lempung } \\
\text { berpasir } \\
* * *\end{array}$ & $0,50-1,46$ \\
\hline 5 & $\begin{array}{l}\text { Xylocarpus } \\
\text { rumphii }\end{array}$ & $>5$ & $0-34$ & $7-8,5$ & $21-26^{*}$ & $\begin{array}{l}\text { Berpasir, } \\
\text { liat } \\
\text { bedebu * }\end{array}$ & $0,50-1,46$ \\
\hline
\end{tabular}

Sumber :

* LPP Mangrove (2006)

**Kepmen LH No. 51 Tahun 2004

*** Kusmana dkk., (2003) dalam Fajar (2013)

****Brady dan Buckman (1982)

***** Ardli et al.(2011) dalam Irawanto (2015)

HASIL DAN PEMBAHASAN

Status dan Kondisi Eksisting Ekosistem Hutan Mangrove

Ekosistem mangrove di sekitar muara Sungai Batang Manggung saat ini memiliki luas \pm 12,2 ha. Pada tahun 2012 vegetasi yang dijumpai didominasi oleh spesies Avicennia marina, Rhizophora spp. dan Xylocarpus granatum dengan luasan 3,5 ha di Desa Ampalu dan 6,0 ha di Desa Apar (Dinas Kelautan dan Perikanan, 2012). Beberapa spesies lain yang juga ditemui yaitu Nypa fruticans, Acanthus ilicifolius, Acrosticum speciosum, Cerbera mangas, Melastoma candidum, Dolicandrone spathaceae, Calophyllum inopyllum,
Baringtonia racemosa, dan Pandanus odoratissima (Sari, 2012).

Berdasarkan keterangan yang diperoleh dari Kepala Desa Ampalu (2015), diketahui bahwa kawasan hutan mangrove di sekitar muara Sungai Batang Manggung merupakan tanah ulayat nagari. Tanah ulayat nagari dikuasai oleh ninik mamak Kerapatan Adat Nagari (KAN) dan dimanfaatkan untuk kepentingan masyarakat nagari, sedangkan pemerintahan nagari bertindak sebagai pihak yang mengatur pemanfaatannya.

Proses pembebasan tanah ulayat milik masyarakat di Nagari Manggung ini 
menimbulkan berbagai macam konflik, meski tidak mengarah pada kekerasan. Menurut penuturan Kepala UPT. Konservasi Penyu Kota Pariaman (2015), proses pembebasan lahan di kawasan mangove masih terkendala karena belum adanya persetujuan dari pemilik tanah dalam melaksanakan kegiatan pembangunan.

\section{Karaktersitik Vegetasi dan Tingkat Kerusakan Ekosistem Hutan Mangrove}

Beberapa jenis mangrove yang sudah diidentifikasi beserta penyebarannya pada masing-masing stasiun dapat dilihat pada Tabel 3 .

Tabel 3. Jenis Mangrove Di Sekitar Muara Sungai Batang Manggung

\begin{tabular}{|c|c|c|c|c|c|c|}
\hline No & $\begin{array}{c}\text { Jenis } \\
\text { Mangove }\end{array}$ & Family & Spesies & $\begin{array}{c}\text { Stasiun } \\
\text { I }\end{array}$ & Stasiun II & $\begin{array}{l}\text { Stasiun } \\
\text { III }\end{array}$ \\
\hline 1 & $\begin{array}{c}\text { Mangrove } \\
\text { asosiasi }\end{array}$ & Acanthaceae & $\begin{array}{l}\text { Acanthus } \\
\text { ilicifolius }\end{array}$ & + & - & + \\
\hline 2 & $\begin{array}{c}\text { Mangrove } \\
\text { sejati }\end{array}$ & Arecaceae & $\begin{array}{c}\text { Nypa } \\
\text { fruticans } \\
\end{array}$ & + & + & + \\
\hline 3 & $\begin{array}{c}\text { Mangrove } \\
\text { sejati }\end{array}$ & $\begin{array}{c}\text { Rhizophoracea } \\
e \\
\end{array}$ & $\begin{array}{l}\text { Rhizophora } \\
\text { mucronata }\end{array}$ & - & + & + \\
\hline 4 & $\begin{array}{c}\text { Mangrove } \\
\text { sejati }\end{array}$ & Sonnetatiaceae & $\begin{array}{c}\text { Sonneratia } \\
\text { caseolaris }\end{array}$ & - & + & + \\
\hline 5 & $\begin{array}{c}\text { Mangrove } \\
\text { minor }\end{array}$ & Meliaceae & $\begin{array}{c}\text { Xylocarpus } \\
\text { rumphii }\end{array}$ & + & - & - \\
\hline & & \multicolumn{2}{|c|}{ Total spesies } & 3 & 3 & 4 \\
\hline
\end{tabular}

Sumber: Hasil Analisis, (2015)

Berdasarkan Tabel 3 diketahui bahwa jenis mangrove yang ditemukan di sekitar muara Sungai Batang Manggung terdiri dari lima jenis. Lima jenis mangrove yang diidentifikasi di lapangan terdiri dari tiga jenis mangrove sejati, satu jenis mangrove minor dan satu jenis mangrove asosiasi. Vegetasi mangrove yang dijumpai di lapangan memiliki karakteristik tersendiri, baik dari segi formasi maupun bentuk adaptasinya terhadap lingkungan. Lebih lanjut mengenai karakteristik vegetasi mangrove di lokasi penelitian, dapat dilihat pada Tabel 4.

Tabel 4. Identifikasi Vegetasi Mangrove di Muara Sungai Batang Manggung

\begin{tabular}{|c|c|c|c|c|}
\hline No & Bentuk Perakaran & Daun & Buah dan Bunga & Spesies \\
\hline 1 & $\begin{array}{l}\text { - } \text { Tidak memiliki akar } \\
\text { yang muncul di } \\
\text { permukaan tanah. } \\
\text { - Diameter batang } \leq 2 \\
\mathrm{~cm}\end{array}$ & 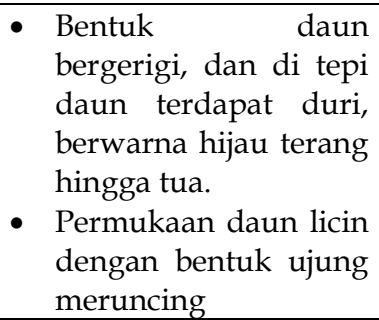 & $\begin{array}{l}\text { - } \begin{array}{l}\text { Mahkota bunga } \\
\text { berwarna agak } \\
\text { putih. } \\
\text { Panjang }\end{array} \\
\text { terletak } 5-4 \mathrm{~cm} \text { dan } \\
\text { tepatnya di pusat } \\
\text { percabangan daun }\end{array}$ & $\begin{array}{l}\text { Acanthus } \\
\text { ilicifolius }\end{array}$ \\
\hline 2 & $\begin{array}{l}\text { - Tidak memiliki akar } \\
\text { nafas yang muncul di } \\
\text { permukaan tanah, } \\
\text { tetapi berupa akar } \\
\text { serabut. }\end{array}$ & 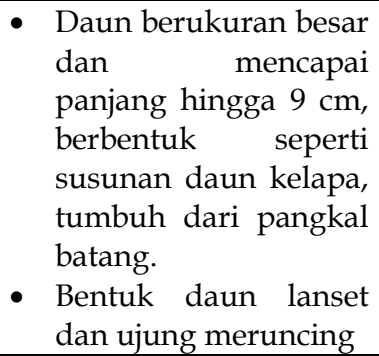 & $\begin{array}{l}\text { Berwarna kuning } \\
\text { menyerupai bola } \\
\text { dan berumpun. }\end{array}$ & $\begin{array}{l}\text { Nypa } \\
\text { fruticans }\end{array}$ \\
\hline 3 & - Memiliki & - Daun berukuran lebar & - Bunga & Rhizophora \\
\hline
\end{tabular}




\begin{tabular}{|c|c|c|c|c|}
\hline No & Bentuk Perakaran & Daun & Buah dan Bunga & Spesies \\
\hline & $\begin{array}{l}\text { gantung yang keluar } \\
\text { dari batang dan } \\
\text { memiliki lentisel } \\
\text { untuk pernafasan. }\end{array}$ & $\begin{array}{l}\text { dengan panjang } \\
\text { mencapai } 20 \mathrm{~cm}, \\
\text { berwarna hijau tua, } \\
\text { dan agak tebal. } \\
\text { - Bentuk daun elips dan } \\
\text { melebar hingga bulat } \\
\text { memanjang dengan } \\
\text { ujung runcing. }\end{array}$ & $\begin{array}{l}\text { putih dan kecil. } \\
\text { Buah berwarna } \\
\text { hijau kecoklatan, } \\
\text { memanjang dan } \\
\text { meruncing pada } \\
\text { bagian bawah } \\
\text { mencapai } 60 \mathrm{~cm} \text {. }\end{array}$ & mucronata \\
\hline 4 & 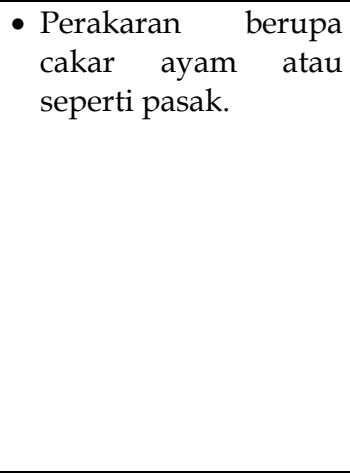 & $\begin{array}{l}\text { - Tangkai daun } \\
\text { berwarna kemerahan, } \\
\text { lebar dan sangat } \\
\text { pendek. Bentuk bulat } \\
\text { memanjang dengan } \\
\text { ujung bundar. }\end{array}$ & 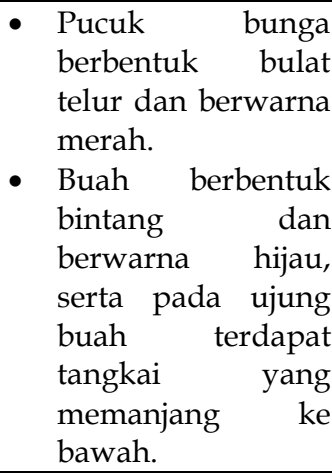 & $\begin{array}{l}\text { Sonneratia } \\
\text { caseolaris }\end{array}$ \\
\hline 5 & $\begin{array}{lr}\text { - Mempunyai } & \text { akar } \\
\text { papan } & \text { yang } \\
\text { memanjang dan } & \text { denopang pohon. }\end{array}$ & $\begin{array}{l}\text { - Daun berwarna hijau } \\
\text { terang hingga gelap, } \\
\text { berukuran kecil dan } \\
\text { ujung daun } \\
\text { meruncing. }\end{array}$ & 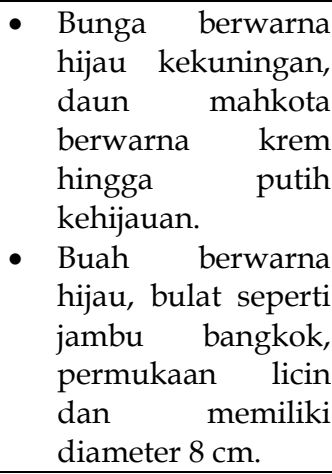 & $\begin{array}{l}\text { Xylocarpus } \\
\text { rumphii. }\end{array}$ \\
\hline
\end{tabular}

Sumber: Hasil Pengolahan Data Primer (2015)

Indeks Nilai Penting (INP)

Hasil perhitungan INP pada tingkat pohon disajikan pada Gambar 3.

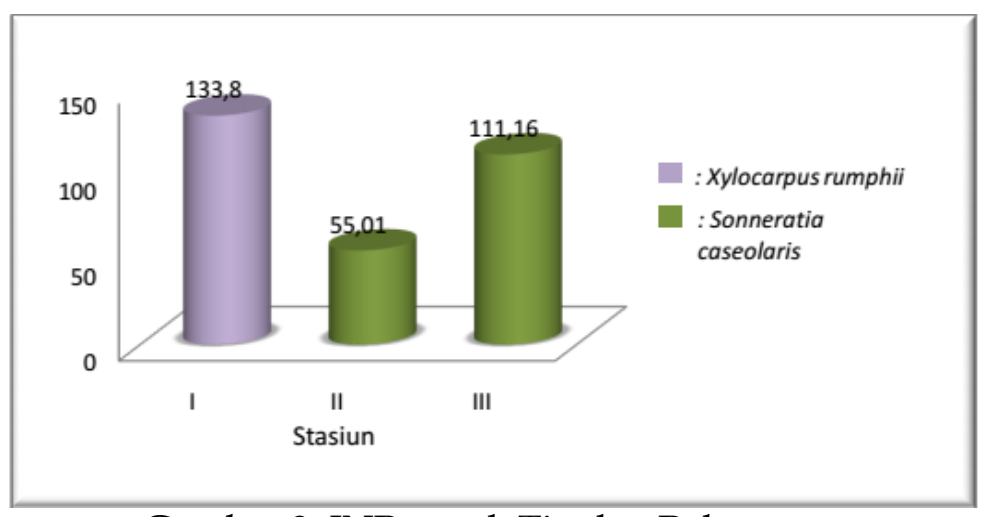

Gambar 3. INP untuk Tingkat Pohon

Pada Gambar 3 diketahui bahwa spesies Xylocarpus rumphii pada Stasiun I memiliki nilai INP tertinggi yaitu 133,8\%. Delapan puluh persen dari vegetasi ini termasuk pada tingkat pohon. Spesies Sonneratia caseolaris mendominasi pada
Stasiun II dengan nilai INP 55,01\%. Pada Stasiun III spesies Sonneratia caseolaris dengan nilai INP 111,16\% memiliki kepadatan cukup tinggi, serta tumbuh terpisah dari kelompok vegetasi lain 
karena berada pada lokasi percabangan sungai.

Penguasaan masing-masing individu pada tingkat pancang disajikan pada Gambar 4. Nilai perhitungan terhadap penguasaan spesies mangrove pada masing-masing stasiun menunjukkan bahwa pada tingkat pancang, Sonneratia caseolaris merupakan spesies yang paling tinggi peranannya daripada spesies lain. Sonneratia caseolaris memiliki INP 46,19\% dengan frekuensi relatif (FR) $20 \%$. Hasil perhitungan INP paling rendah terdapat pada spesies Nypa fruticans yaitu 7,2 pada Stasiun I, dan 18,5 pada Stasiun II. Rendahnya penguasaan spesies ini disebabkan karena terdapat perubahan pada ekosistem. Spesies ini tumbuh dengan baik pada zona arah darat, sementara di lokasi penelitian spesies ini dijumpai pada formasi depan.

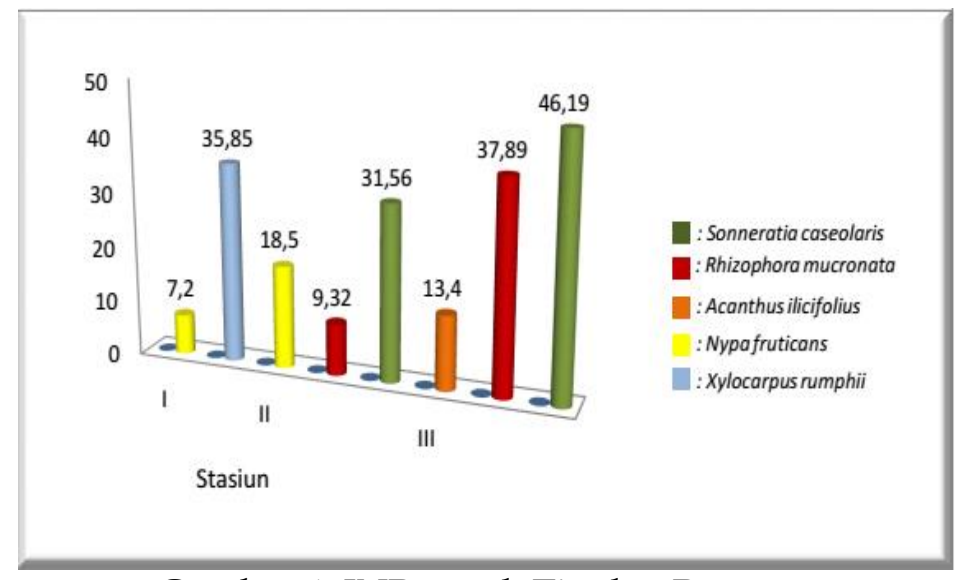

Gambar 4. INP untuk Tingkat Pancang

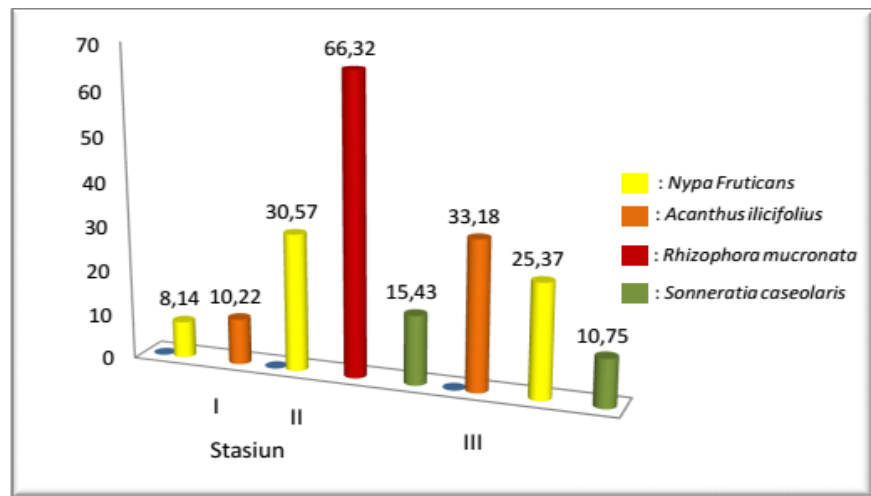

Gambar 5. INP untuk Tingkat Semai dan Tumbuhan Bawah

Hasil perhitungan INP pada tingkat semai dan tumbuhan bawah ditunjukkan pada Gambar 5 di atas. Spesies yang paling mendominasi untuk tingkat semai dan tumbuhan bawah yaitu Rhizophora mucronata pada Stasiun II dengan nilai INP $66,32 \%$. Tingginya penguasaan spesies Rhizophora mucronata karena berada pada wilayah rehabilitasi yang dilakukan oleh Dinas Kelautan dan Perikanan Kota Pariaman Tahun 2014. Jika spesies ini mampu hidup dengan baik, maka tingkat kerapatan individu mencapai 2766 individu/ha.

Nilai INP paling terdapat pada spesies Nypa fruticans dengan nilai 8,14. Rendahnya penguasaan spesies disebabkan karena vegetasi lebih didominasi oleh tingkat pohon dan pancang, serta kurang lancarnya aliran air. Hal ini sesuai dengan pendapat Hossain dan Islam (2015), bahwa Nipah 
hanya dapat hidup dengan baik pada wilayah berair payau dan perakaran yang selalu terendam oleh air, sehingga mayoritas spesies ini lebih banyak menempati wilayah rataan pasang surut.

Secara umum, dapat disimpulkan bahwa tingkat penguasaan vegetasi mangrove didominasi oleh tingkat pohon. Hal ini ditunjang oleh faktor luas bidang dasar (LBD) dan diameter pohon. Kedua faktor ini akan berbanding lurus dengan luas area yang ditempati, sehingga memiliki penguasaan yang lebih tinggi dan memiliki peran penting dalam ekosistem mangrove.

Penutupan Tumbuhan
Berdasarkan perhitungan tutupan tumbuhan hutan mangrove di sekitar muara Sungai Batang Manggung diketahui bahwa persentase tertinggi terdapat pada Stasiun I, yaitu $44 \%$, Stasiun III $40 \%$, dan terendah pada Stasiun II yaitu 16\% (Tabel 5.). Jika mengacu pada Keputusan Menteri Negara Lingkungan Hidup No. 201 Tahun 2004, penutupan tumbuhan $<50 \%$ termasuk dalam kategori rusak. Berubahnya kondisi lingkungan akibat normalisasi Sungai Batang Manggung berpengaruh pada salinitas air, $\mathrm{pH}$ air, bahan organik tanah dan sirkulasi air yang kurang lancar.

Tabel 5. Penutupan Vegetasi Hutan Mangrove di Sekitar

Muara Sungai Batang Manggung

\begin{tabular}{|c|c|r|}
\hline Stasiun & Jenis Mangrove & Rci = (Ci/ $/ \mathbf{C}) \times \mathbf{1 0 0}$ \\
\hline I & Xylocarpus rumphii & 44 \\
\hline II & Sonneratia caseolaris & 16 \\
\hline III & Sonneratia caseolaris & 40 \\
\hline Jumlah & & $\mathbf{1 0 0}$ \\
\hline
\end{tabular}

Sumber: Hasil Pengolahan Data Primer (2015)

\section{Kerapatan Mangrove}

Hasil perhitungan kerapatan vegetasi mangrove di sekitar muara Sungai Batang Manggung ditunjukkan Tabel 6. Berdasarkan Tabel 5. diketahui bahwa untuk tingkat pohon, kerapatan vegatasi mangrove termasuk jarang, karena jumlah individu <1000/ha. Vegetasi mangrove pada tingkat semai dan tumbuhan bawah pada Stasiun I termasuk dalam kriteria jarang, dengan kerapatan 200 individu/ha. Hal ini disebabkan karena pada stasiun I lebih didominasi oleh vegetasi tingkat pancang dan pohon. Sedangkan vegetasi tingkat semai pada Stasiun II dan III termasuk dalam kriteria sangat padat, begitu pula untuk tingkat pancang.

Tabel 6. Kerapatan Vegetasi Mangrove BerdasarkanKriteria Baku Kerusakan Hutan Mangrove

\begin{tabular}{|c|r|c|r|c|r|c|}
\hline \multirow{2}{*}{ Stasiun } & \multicolumn{7}{|c|}{ Kerapatan (Individu/ha) } \\
\cline { 2 - 7 } & Semai & Kriteria & Pancang & Kriteria & Pohon & Kriteria \\
\hline I & 200 & Jarang & 2.267 & Sangat padat & 667 & Jarang \\
\hline II & 4.234 & Sangat padat & 1.900 & Sangat padat & 67 & Jarang \\
\hline III & 1.966 & Sangat padat & 5.634 & Sangat padat & 433 & Jarang \\
\hline
\end{tabular}

Sumber: Hasil Pengolahan Data Primer (2015)

Kondisi Fisik-Kimia Ekosistem Hutan

Mangrove

Oksigen Terlarut (Dissolved Oxygen)

Berdasarkan hasil pengukuran pada perairan hutan mangrove diketahui bahwa konsentrasi oksigen terlarut paling tinggi terdapat pada Stasiun I yaitu 6,2 $\mathrm{mg} / \mathrm{l}$. Sedangkan konsentrasi oksigen terendah pada Stasiun III yang ditemukan pada titik 9 yaitu 5,0 mg/l. Jika merujuk 
pada Keputusan Menteri Negara Lingkungan Hidup No. 51 Tahun 2004, dapat disimpulkan bahwa pada masingmasing stasiun pengamatan, jumlah oksigen terlarut sudah sesuai dengan baku mutu dan persyaratan hidup mangrove.

\section{Salinitas Air}

Hasil pengukuran rata-rata salinitas air pada tiap stasiun pengamatan menunjukkan hasil yang tidak jauh berbeda. Salinitas paling tinggi terdapat pada Stasiun I yaitu 0,048 ppt, Stasiun II 0,33 ppt, dan paling rendah pada Stasiun III yaitu 0,031 ppt. Tingginya salinitas pada Stasiun I disebabkan karena lokasi ini berdekatan dengan pintu air, tempat terjadinya pertukaran air tawar dan air asin sewaktu terjadi pasang.

Berdasarkan hasil pengukuran salinitas perairan dapat disimpulkan bahwa ekosistem mangrove di sekitar muara Sungai Batang Manggung dapat berkembang dengan baik. Hal ini sesuai Kepmen LH. No. 51 Tahun 2004 bahwa kondisi salinitas perairan untuk vegetasi mangrove antara 0-34 ppt.

pH Air

Berdasarkan hasil pengukuran lapangan diketahui bahwa rata-rata $\mathrm{pH}$ air di lokasi penelitian yaitu antara 5,3-6. Nilai $\mathrm{pH}$ air paling tinggi terdapat pada Stasiun I dengan nilai $\mathrm{pH} 6$, dan paling rendah terdapat pada Stasiun II dengan nilai $\mathrm{pH} 5,3$. Kandungan $\mathrm{pH}$ berkaitan erat dengan suhu udara, salinitas dan aktivitas biologi (Stumm, 1981).

Nilai rata-rata $\mathrm{pH}$ 5,3-6 pada perairan ekosistem mangrove belum sesuai dengan baku mutu lingkungan dan syarat hidup vegetasi mangrove. Nilai $\mathrm{pH}$ perairan yang cocok untuk biota laut berada antara 7-8,5 dan nilai $\mathrm{pH}$ perairan alami 6,5-9 (Kepmen LH No. 51 Tahun 2004; Boyd, 1988 dalam Fajar, 2013). Rendahnya nilai $\mathrm{pH}$ mengindikasikan bahwa terdapat ketidakseimbangan reaksi kimia pada perairan hutan mangrove, yang secara tidak langsung akan mempengaruhi pertumbuhan vegetasi mangrove.

\section{Suhu Udara}

Berdasarkan hasil pengukuran diketahui bahwa rentang nilai suhu udara pada lokasi penelitian berkisar $28,4-32{ }^{\circ} \mathrm{C}$. Suhu udara pada tiap stasiun pengamatan menunjukkan nilai yang variatif dan berdasarkan hasil $t$ test satu sampel dapat disimpulkan terdapat perbedaan suhu udara pada masingmasing stasiun pengamatan.

Jika dibandingkan dengan

kesesuaian suhu udara pada masingmasing spesies dapat diketahui bahwa semua spesies yang dijumpai pada lokasi penelitian dapat hidup dengan baik, kecuali Xylocarpus rumphii. Xylocarpus rumphii yang hanya dijumpai pada Stasiun I memiliki toleransi suhu udara 21-26 ${ }^{\circ} \mathrm{C}$ (LPP Mangrove, 2006), sementara suhu udara rata-rata pada saat pengukuran $30,7{ }^{\circ} \mathrm{C}$. Vegetasi yang tumbuh di atas suhu optimum biasanya menghasilkan produksi yang rendah (Setiawan, 2010). Kondisi ini dapat ditunjukkan dengan tidak adanya vegetasi tingkat semai pada spesies Xylocarpus rumphii.

\section{Jenis Subtrat}

Berdasarkan hasil analisis di laboratorium, diketahui bahwa tekstur substrat pada lokasi penelitian terdiri dari pasir, pasir berlempung, dan lempung berdebu. Secara keseluruhan kondisi tekstur yang ditemukan pada tiap stasiun pengamatan sudah sesuai dengan pertumbuhan dan perkembangan vegetasi mangrove.

\section{Bahan Organik}

Bahan organik yang dijumpai di lokasi penelitian cukup bervariasi. Bahan organik paling rendah terdapat di Stasiun I, petak ukur 1 yaitu $0,22 \%$, dan paling tinggi terdapat pada petak ukur 3 yaitu $1,83 \%$. Rata-rata kandungan bahan organik di lokasi penelitian berkisar antara 0,53\%-1,01\%. Berdasarkan hasil analisis laboratorium tersebut dapat disimpulkan bahwa kandungan bahan organik di lokasi penelitian sudah sesuai dan mendukung untuk pertumbuhan dan perkembangan vegetasi mangrove. 
Namun, beberapa lokasi memiliki kandungan bahan organik di bawah standar.

\section{KESIMPULAN}

Spesies yang ditemukan di sekitar muara Sungai Batang Manggung yaitu Acanthus ilicifolius, Nypa fruticans, Rhizophora mucronata, Sonneratia caseolaris, dan Xylocarpus rumphii. Nilai INP untuk tingkat pohon paling tinggi terdapat pada spesies Xylocarpus rumphii $(133,8 \%)$ yang ditemukan pada Stasiun I. Nilai INP untuk tingkat pancang paling tinggi terdapat pada spesies Sonneratia caseolaris $(46,19 \%)$, yang ditemukan pada stasiun III, dan untuk tingkat semai dan tumbuhan bawah nilai INP paling tinggi terdapat pada spesies Rhizophora mucronata $(66,32 \%)$ pada Stasiun II.

Hutan mangrove untuk tingkat pohon termasuk rusak, dengan penutupan $<50 \%$ dan kerapatan $<1000$ pohon/ha. Sedangkan untuk tingkat pancang, semai dan tumbuhan bawah termasuk dalam kategori baik. Hal ini ditunjukkan dengan kerapatan individu > 1500 pohon/ha.

Hasil analisis kondisi fisik-kimia ekosistem hutan mangrove secara umum sudah sesuai dengan syarat hidup untuk vegetasi mangrove. Namun, hasil pengukuran $\mathrm{pH}$ perairan yang berada di bawah 7 mengindikasikan adanya ketidakseimbangan reaksi kimia pada perairan ekosistem mangrove. Pengukuran suhu udara yang berada di atas syarat hidup spesies Xylocarpus rummphii menyebabkan rendahnya produksi vegetasi, terutama untuk tingkat semai.

\section{DAFTAR PUSTAKA}

Armono, H.D., Pratikto, W.A., dan Suntoyo. (1996). Perencanaan Fasilitas Pantaidan Laut. Surabaya: BPFEYogyakarta.
Buckman, H.O., dan Brady, N.C. (1982). Ilmu Tanah. Jakarta: PT. Bhratara Karya Aksara.

Dale, P.E.R., Knight, J.M, Dwyer, P.G. (2014). Mangrove Rehabilitation: A review Focusing On Ecological And Institusional Issues. Wetlands Ecol Manage. 22:587-604.

Dinas Kelautan dan Perikanan. (2012). Profil Kelautan dan Perikanan Tahun 2012.

Fajar, A., Oetama, D., Afu, A. (2013). Studi Kesesuaian Jenis Untuk Perencanaan Rehabilitasi Ekosistem Mangrove di Desa Wawatu Kecamatan Moramo Utara Kabupaten Konawe Selatan. Jurnal Mina Laut Indonesia, 03, 164-176.

Faturrohmah, S. Dan Marjuki, B. (2017). Identifikasi Dinamika Spasial Sumberdaya Mangrove di Wilayah Pesisir Kabupaten Demak Jawa Tengah. Majalah Geografi Indonesia, 31(1), 56-64.

Feka, Z. N. (2015). Sustainable Management of Mangrove Forests in West Africa: A New Policy Perspective. Ocean $\mathcal{E}$ Coastal Management. 116. 341-352.

Hossain, M. F. dan Islam, M. A. (2015). Utilization of Mangrove Forest Plant: Nipa Palm (Nypa fruticans Wurmb.). American Journal of Agriculture and Forestry, 3(4), 156160.

Irawanto, R., Ariyanto, E.E., Hendrian, R. (2015). Jeruju (Acanthus ilicifolius): Biji, Perkecambahan dan Potensinya. Prosemnas Masy. Biodiv. Indonesia, I (5), 1011-1018.

Kementrian Lingkungan Hidup. (2004). Strategi Nasional dan Rencana Aksi Pengelolaan Lahan Basah Indonesia. Jakarta: Komite Nasional 
Pengelolaan Ekosistem Lahan Basah.

Kustanti, A., Nugroho, B., Nurrochmat, D.R., dan Okimoto, Y. (2014). Evolusi Hak Kepemilikan Dalam Pengelolaan Ekosistem Hutan Mangrove Di Lampung Mangrove Center. Risalah Kebijakan Pertanian dan Lingkungan, 1(3), 143-158.

Onrizal. (2008). Teknik Survey Dan Analisis Data Sumberdaya Mangrove. Pelatihan Pengelolaan Hutan Mangrove Berkelanjutan Untuk Petugas/Penyuluh Kehutanan.
Tanjung Pinang: Balai Pengelolaan Hutan Mangrove Wilayah II dan Japan International Cooperation Agency (JICA).

Ramdhan, M., dan Abdillah, Y. (2012). Pemetaan Tingkat Kerentanan Pesisir Wilayah Kota Pariaman. Jakarta: Balitbang KP.

Sari, T.M. (2012). Studi Etnobotani Pada Hutan Mangrove Di Kenagarian Mangguang Kota Pariaman. Skripsi. Padang: STKIP PGRI Sumatera Barat. 